\title{
Conformational properties of biocompatible poly(2-ethyl-2-oxazoline)s in phosphate buffered saline
}

\author{
Alexander S. Gubarev ${ }^{\mathrm{a}}$, Bryn D. Monnery ${ }^{\mathrm{b}}$, Alexey A. Lezov ${ }^{\mathrm{a}}$, Ondrej Sedlacek ${ }^{\mathrm{b}, \mathrm{c}}$, Nikolai V. \\ Tsvetkova ${ }^{\mathrm{a}}$, Richard Hoogenboom ${ }^{\mathrm{b}, *}$, Sergey K. Filippov ${ }^{\mathrm{c}, *}$
}

\begin{abstract}
Inspired by the increasing popularity of poly(2-ethyl-2-oxazoline) (PEtOx) for biomedical applications, this study reports the complete and thorough solution analysis of the homologous series of biocompatible PEtOx samples in a very broad range of molecular weights ranging from $11.2 \times$ $10^{3}, \mathrm{~g} / \mathrm{mol}$ up to $260 \times 10^{3}, \mathrm{~g} / \mathrm{mol}$. The main focus of the research was on the determination of conformational properties of PEtOx macromolecules at the temperature of $37^{\circ} \mathrm{C}$ in phosphate buffered saline (PBS) buffer simulating the parameters of physiological media. The polymers were studied in PBS solutions by analytical ultracentrifugation, dynamic light scattering (DLS), translational diffusion, and intrinsic viscosity measurements in a temperature range from $15{ }^{\circ} \mathrm{C}$ up to $72{ }^{\circ} \mathrm{C}$. The complete set of Kuhn-Mark-Houwink-Sakurada scaling relations revealed linear trends over the whole range of the studied molar masses, while the determined scaling indices at $37^{\circ} \mathrm{C}$ correspond to the coil conformation in a thermodynamically good solvent $\left([\eta]=0.045 \times M^{0.62}, s_{0}=0.010 \times M^{0.46}\right.$ and $D_{0}=1750 \times M^{-0.54}$ ). Based on the intrinsic viscosity values (most sensitive characteristic to the size variations of polymer coils, $[\eta] \sim r^{3}$ ), it was demonstrated that PEtOx macromolecules in PBS solutions undergo a transition from swollen polymer coils with gradual deterioration of thermodynamical quality of solutions within the temperature range of $15-45^{\circ} \mathrm{C}$, reaching $\theta$-conditions at $55^{\circ} \mathrm{C}$ with further precipitation at $62-72^{\circ} \mathrm{C}$. Also, to our best knowledge, the conformational parameters (equilibrium rigidity/the Kuhn segment length and the diameter of polymer chain) of PEtOx macromolecules were evaluated in physiological conditions for the first time and constitute $A=1.8 \pm 0.3 \mathrm{~nm}$ and $d=0.7 \pm 0.4 \mathrm{~nm}$. These equilibrium rigidity values classify PEtOx as a flexible macromolecule with similar rigidity to poly(ethylene glycol). For the first time we were able to demonstrate a direct influence of thermosensitivity on the rigidity of biocompatible polymer: PEtOx. The Kuhn segment length is undoubtedly decreasing when approaching the LCST transition temperature.
\end{abstract}


Poly(2-ethyl-2-oxazoline)s (PEtOx) nowadays are very promising candidates for substitution of classical biocompatible homopolymers such as poly(ethylene glycol) (PEG), poly( $N$-vinylpyrrolidone) (PVP) or poly(hydroxypropyl methacrylate) (PHPMA). ${ }^{1,2}$ To design polymer therapeutics based on PEtOx, a detailed knowledge of the conformational properties of the polymer chains is required in physiological conditions. The polymer chain conformation is of primary importance for the fate of a macromolecule in drug delivery issue. Flexible polymers have higher glomerular permeability and thus a shorter blood circulation half-life compared to more rigid polymers of the same size. On the other hand, more flexible polymers diffuse more efficiently in the tumor tissue, which leads to their increased tumor accumulation. ${ }^{3,4}$ The importance of the chain conformation of several biologically relevant macromolecules such as actin ${ }^{5}$ or $\mathrm{DNA}^{6}$ on their functionality has been reported in literature as well. DNA compaction is, probably, the most spectacular example of conformation changes as the DNA persistence length strongly decreases after complexation with mono or divalent ions. ${ }^{6}$ Conformational analysis can be performed by a combination of rigorous hydrodynamic methods such as analytical ultracentrifugation, translational diffusion, and intrinsic viscosity measurements through Kuhn-Mark-Houwink-Sakurada (KMHS) scaling relations. ${ }^{7-10}$ A broad range of molecular weights and low dispersity is mandatory for such a study. Therefore, such in depth knowledge on the conformational properties of PEtOx is absent as for many years high molar mass defined poly(2oxazoline)s were synthetically inaccessible due to the sensitivity of the cationic ring-opening polymerization to nucleophilic impurities in combination with unavoidable intrinsic chain transfer side reactions (CROP). ${ }^{11}$ Recently, some of us developed an improved synthetic methodology that now allows the preparation of high molar mass poly(2-oxazoline)s by a combination of rigorous purification, change of solvent and lower temperature allowing in depth analysis of the conformational properties of PEtOx in solution. ${ }^{12}$ Recently, related work was published on solution properties of PEtOx, but in depth conformational analysis and its temperature dependence was not addressed. ${ }^{13}$

In this work, we have investigated the conformation and solution properties of thermoresponsive biocompatible PEtOx homopolymers in PBS to study the equilibrium rigidity and other parameters as a function of temperature. The determined molar masses of the suited PEtOx are determined to be in range from $11.2 \times 10^{3} \mathrm{~g} / \mathrm{mol}$ up to $260 \times 10^{3} \mathrm{~g} / \mathrm{mol}$ (Table 1). These absolute values of the molar masses together with sedimentation coefficients, and Gralen constants were evaluated by the classical sedimentation-diffusion analysis as described in section S2 of the electronic supporting information (ESI). The intrinsic viscosity values were determined from viscometry measurements, whereas diffusion coefficient value was obtained from both isothermal diffusion and DLS experiments (ESI).

The comparison of the hydrodynamic characteristics of PEtOx with different molar masses allows to establish the classical KMHS scaling relationships. In general they can be written as follows:

$$
P_{i}=K_{i j} P_{j}^{b_{i j}}
$$

where $P_{i}$ is one of the hydrodynamic characteristics and $P_{j}$ is another hydrodynamic characteristic or the molar mass.

The corresponding KMHS plots are presented in Figure 1 and the parameters of the scaling indices are given in Table S4 (Supporting Information). 
Next, the experimental errors associated with the determination of the scaling indices and the known relations connecting the scaling indices can be taken into account with:

$$
\left|b_{D}\right|=\left(1+b_{\eta}\right) / 3,\left|b_{D}\right|+b_{s}=1
$$

Table 1. The intrinsic viscosity [ $\eta$ ], diffusion $D_{0}$ and sedimentation coefficients $s_{0}$, Gralen constants $k_{\mathrm{s}}$, hydrodynamic invariants $A_{0}$ and $\beta_{\mathrm{s}}$, molecular weights $M_{\mathrm{sD}}$ and $M_{\mathrm{w}}$, polydispersity indexes $\bigoplus_{\text {, the }}$ relative contour length $L / A$ and the end-to-end distance determined for PEtOx samples in PBS solutions at $37^{\circ} \mathrm{C}$.

\begin{tabular}{|c|c|c|c|c|c|c|c|c|c|c|c|}
\hline$\underset{\mathrm{e}}{\text { Sampl }}$ & $\begin{array}{l}{[\eta]_{3}} \\
\mathrm{~cm}^{-1} \\
\mathrm{~g}^{-1}\end{array}$ & $\begin{array}{l}<D_{0}>10^{7} \\
, \mathrm{~cm}^{2} \mathrm{~s}^{-1}\end{array}$ & $\begin{array}{c}s_{0} 10^{13} \\
\quad, \\
\mathrm{~s}\end{array}$ & $\begin{array}{l}k_{\mathrm{s}}, \\
\mathrm{cm} \\
{ }^{3} \mathrm{~g}^{-}\end{array}$ & $\begin{array}{l}\beta_{\mathrm{s}_{-7}} 10 \\
\mathrm{~mol}_{1 / 3}^{-}\end{array}$ & $\begin{array}{c}A_{0} 10^{10} \\
2^{\mathrm{g} \mathrm{cm}} \mathrm{cm}^{-2} \mathrm{~K}^{-} \\
{ }^{1} \mathrm{~mol}_{1 / 3}^{-}\end{array}$ & $\begin{array}{l}{ }^{*} M_{\mathrm{sD} 10} 10 \\
\mathrm{~g} \mathrm{~mol}^{-1}\end{array}$ & $\begin{array}{l}{ }^{* *} M_{\mathrm{w}} 10 \\
\mathrm{~g} \mathrm{~mol}^{-1}\end{array}$ & $\bigoplus^{* *}$ & $L / A$ & $\begin{array}{c}\left\langle h^{2}>^{1 / 2}\right. \\
\mathrm{nm}\end{array}$ \\
\hline $\mathrm{P} 1$ & $\begin{array}{c}13 . \\
8\end{array}$ & 10.8 & 0.69 & 25 & 1.17 & 2.85 & 11.2 & 11 & $\begin{array}{c}1.0 \\
5\end{array}$ & 24 & 9 \\
\hline $\mathrm{P} 2$ & $\begin{array}{c}19 . \\
0\end{array}$ & 8.2 & 0.90 & 32 & 1.15 & 2.89 & 19.2 & 19 & $\begin{array}{c}1.0 \\
4\end{array}$ & 41 & 12 \\
\hline P3 & $\begin{array}{c}31 . \\
4\end{array}$ & 5.6 & 1.36 & 52 & 1.21 & 3.04 & 43 & 43 & 1.0 & 90 & 18 \\
\hline P4 & $\begin{array}{c}39 . \\
6\end{array}$ & 4.7 & 1.59 & 54 & 1.15 & 3.07 & 60 & 62 & 1.1 & $\begin{array}{c}13 \\
0\end{array}$ & 22 \\
\hline P5 & $\begin{array}{c}55 . \\
7\end{array}$ & 3.4 & 2.06 & 85 & 1.17 & 3.03 & 105 & 110 & 1.1 & $\begin{array}{c}22 \\
0\end{array}$ & 30 \\
\hline P6 & $\begin{array}{c}84 . \\
4\end{array}$ & 2.5 & 2.83 & 150 & 1.28 & 3.15 & 200 & 216 & 1.1 & $\begin{array}{c}42 \\
0\end{array}$ & 41 \\
\hline P7 & 99 & 2.2 & 3.30 & 160 & 1.27 & 3.21 & 260 & 330 & $\begin{array}{c}1.1 \\
5\end{array}$ & $\begin{array}{c}55 \\
0\end{array}$ & 47 \\
\hline
\end{tabular}

* - the values are found by sedimentation diffusion analysis; ** - SEC-MALS data.

(a)

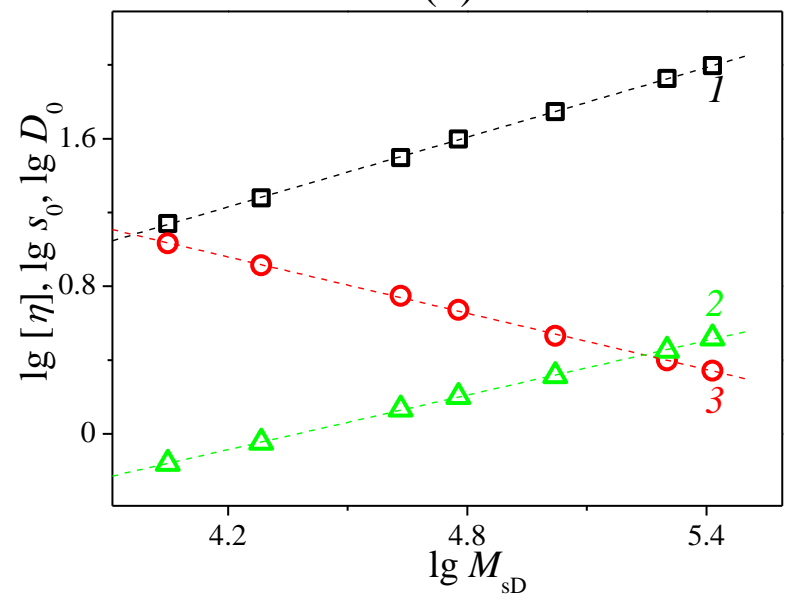

(b)

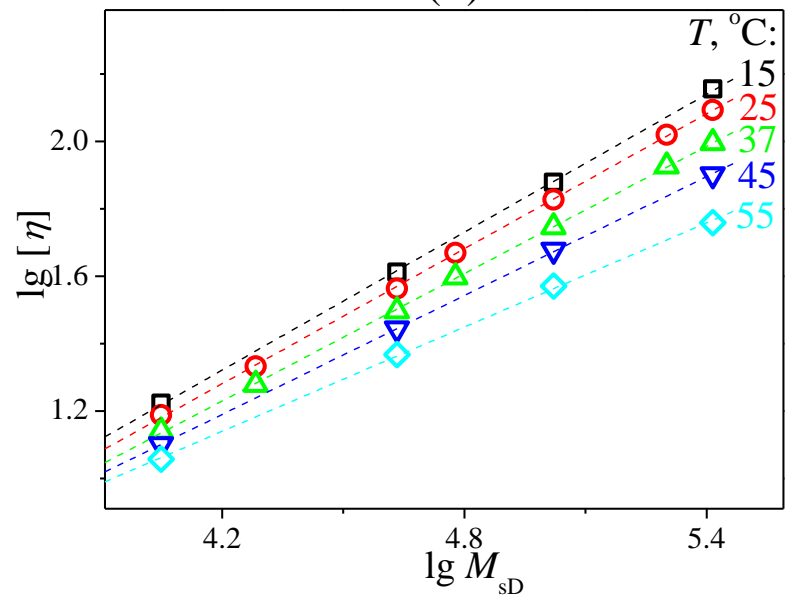



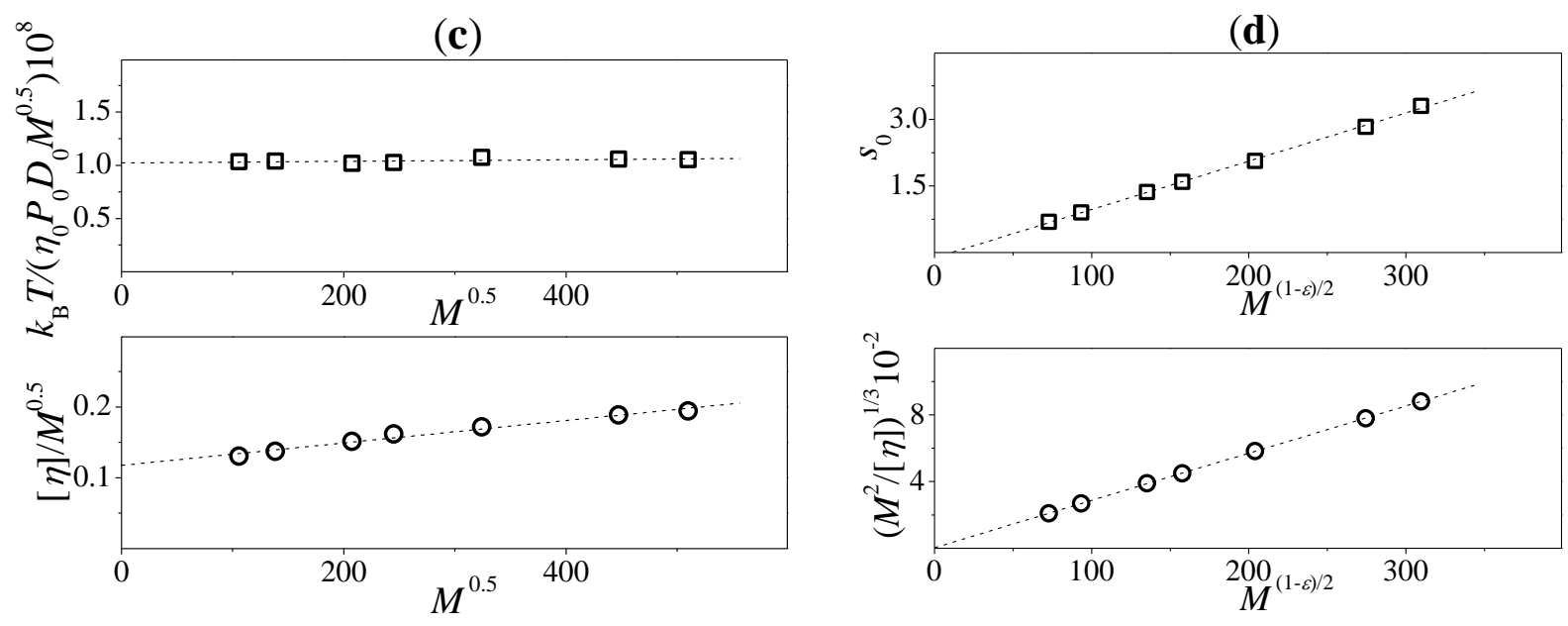

Figure 1.The KMHS relationships for intrinsic viscosity (1) sedimentation coefficients (2) and diffusion coefficients (3) of PEtOx samples in PBS solutions at $37{ }^{\circ} \mathrm{C}$ (a); the demonstration of sensitivity of scaling indexes $b_{\eta}$ on the temperature in PBS solutions (temperature is presented next to the dependences) (b); Fixman-Stockmayer and CowieBywater extrapolation procedures at $37{ }^{\circ} \mathrm{C}$ (c); the Gray-Bloomfield-Hearst theory application to obtained hydrodynamic data at $37^{\circ} \mathrm{C}$ (d).

Then, the behavior of PEtOx macromolecules in PBS buffer at $37{ }^{\circ} \mathrm{C}$ in the studied range of molar masses could be described by the following KMHS relationships:

$[\eta]=0.045 \times M^{0.62}, s_{0}=0.010 \times M^{0.46}$

and

$D_{0}=1750 \times M^{-0.54}$

The insignificant deviations of hydrodynamic scaling indexes from the value of $|0.5|$ suggest that the studied system of PEtOx in PBS at $37{ }^{\circ} \mathrm{C}$ is in a thermodynamically good solvent and the deviations are attributed to the occurrence of excluded volume effects.

The conformational parameters, including equilibrium rigidity - $A$ (statistical segment length/Kuhn segment length) and the transversal dimension of the polymer chain $-d$ (diameter of the polymer chain), were calculated as the next step.

Usually, the initial evaluations of unperturbed dimensions of polymer chains found in thermodynamically good solvents are accomplished with the following extrapolation procedures: ${ }^{14,15}$

$$
\frac{[\eta]}{M^{0.5}}=\Phi_{0} \times\left[\left(\frac{A}{M_{L}}\right)^{1.5}+0.51 B M^{0.5}\right]
$$




$$
\frac{1}{\eta_{0} P} \frac{k_{B} T}{D M^{0.5}}=\left(\frac{A}{M_{L}}\right)^{0.5} \times\left[1+0.2 B\left(\frac{M_{L}}{A}\right)^{1.5} M^{0.5}\right]
$$

where $M_{L}=M_{0} / \lambda$ is the molar mass per unit chain length, $\lambda$ is the projection of a monomer unit to the direction of fully extended polymer chain, $M_{0}$ is the molar mass of a monomer unit. In order to solve these equations, the $M_{L}$ value must be known. We have calculated the $M_{L}$ value to be equal to $2.62 \times$ $10^{9} \mathrm{~g} /(\mathrm{mol} \mathrm{cm})$ on the basis of the value of $\lambda=3.78 \times 10^{-8} \mathrm{~cm}$ and the known molar mass of the monomer unit $-M_{0}=99.13 \mathrm{~g} / \mathrm{mol}$.

Thus, the equilibrium rigidity value was calculated both from the rotational $A_{h}=1.5 \pm 0.1 \mathrm{~nm}$ and translational friction experiments $A_{f}=2.7 \pm 0.1 \mathrm{~nm}$ using Eq. (3) and (4), correspondingly. The obtained values for equilibrium rigidity $A$ correspond to flexible polymer chains that lay in the following range: $1.5 \leq A, n m \leq 2.7$.

Further, we have performed more accurate determination of the equilibrium rigidity value using the Grey-Bloomfield-Hearst theory which describes the dependence of sedimentation coefficient of a wormlike necklace and also encounters for both long-range interactions and draining effects (the finite quantity of the polymer chain diameter). ${ }^{16}$ In the region $L / A>2.3$ there is a linear dependence set by the following equation:

$[s] N_{A} P_{0}=\frac{3}{(1-\varepsilon)(3-\varepsilon)} \frac{M_{L}^{(1+\varepsilon) / 2}}{A^{(1-\varepsilon) / 2}} M^{(1-\varepsilon) / 2}+\frac{P_{0} M_{L}}{3 \pi}[\ln A / d-d / 3 A-\varphi(\varepsilon)]$,

where $\varphi(\varepsilon)=1.431+2.635 \varepsilon+4.709 \varepsilon^{2}$ and $\varepsilon$ is the parameter characterizing thermodynamic quality of a solvent. The parameter $\varepsilon$ can be assessed from the scaling indexes of KMHS equations:

$\varepsilon=\left(2 b_{h}-1\right) / 3=\left(2\left|b_{D}\right|-1\right)$.

Assuming the equivalency of a macromolecular size in experiments involving rotational and translational motion of a polymer chain it is possible to use the substitute $\left([s] P_{0} N_{A}=\left(M^{2} \Phi_{0} /[\eta]\right)^{1 / 3}\right.$ in Eq. (19). ${ }^{17}$ The dependences of $[s] P_{0} N_{A}$ and $M^{2} \Phi_{0} /[\eta]^{1 / 3}$ as a function of $M^{(1-\epsilon) / 2}$ are shown in Figure 1c,d. The slopes of the corresponding dependence will eventually lead to the values of the equilibrium rigidity, whereas the intercept allows to estimate the values of the diameter of the polymer chain. Consequently, the following values of $A$ and $d$ were found: $A_{f}=2.08 \pm 0.07 \mathrm{~nm}, d_{f}=$ $1.1 \pm 0.3 \mathrm{~nm}$ and $A_{\eta}=1.51 \pm 0.01 \mathrm{~nm}, d_{\eta}=0.2 \pm 0.1 \mathrm{~nm}$ for the translational frictional $\left(A_{f}\right)$ and viscometric $\left(A_{\eta}\right)$ data respectively. The slight difference between $A_{f}$ and $A_{\eta}$ values is attributed to certain disagreements between the theories describing translational and rotational friction for the chain molecular models, which was widely discussed in literature. ${ }^{18}, 19$ The obtained equilibrium rigidity values, $\left(A_{f}\right)$ and $\left(A_{\eta}\right)$, are in a good agreement, therefore we used further their averaged value: $\langle A\rangle=1.8 \pm 0.3 \mathrm{~nm}$. The found value of $A$ correlates well with ones determined for contiguous water-soluble flexible macromolecules: PNIPAM $A=3.0 \mathrm{~nm}$, PHPMA $A=1.7 \pm$ $0.1 \mathrm{~nm}$, PEG and PEI $A=1.9 \mathrm{~nm}$ and PVP $A=2.0 \pm 0.4 \mathrm{~nm}$ indicating similar rigidity for PEtOx (Table 2). ${ }^{9,17}$

The indirect estimations of Kuhn segment length was previously reported by Sung and Lee for PEtOx fractions with moderate dispersity in THF solutions showing ambiguous scaling indexes data. ${ }^{20}$ 
Nevertheless the earlier found value is in a good agreement with the value obtained in our study for PEtOx in PBS at $37{ }^{\circ} \mathrm{C}$.

Additionally, the diameter of the polymer chain can also be estimated from the value of the partial specific volume using the following relationship: ${ }^{21}$

$$
d=\sqrt{\frac{4 M_{0} v}{\pi \lambda N_{A}}}
$$

The calculated value of $0.69 \mathrm{~nm}$ is is in agreement with the values determined based on the sedimention and viscosity data, which, in turn, provides the appropriate level of trust to the determined values and finally allows to reach the desired one $\langle d\rangle=0.7 \pm 0.4 \mathrm{~nm}$.

\begin{tabular}{|c|c|c|c|c|}
\hline Polymer & $\begin{array}{l}A, \\
\mathrm{~nm}\end{array}$ & solvent & $\begin{array}{l}\text { Method of } \\
\text { Kuhn length } \\
\text { determination }\end{array}$ & Ref. \\
\hline PEG & $\begin{array}{c}1.9 \pm \\
0.1 \\
(2 x \\
0.93)\end{array}$ & $\begin{array}{c}\text { Water; } \\
\text { water + } \\
0.45 \mathrm{M} \\
\mathrm{K}_{2} \mathrm{SO}_{4}\end{array}$ & Viscometry & 22 \\
\hline PNIPAM & 3.0 & Water & $\mathrm{C} \infty$ & 23 \\
\hline PVP & $\begin{array}{c}1.7 \pm \\
0.1 \\
2.4 \pm \\
0.1\end{array}$ & $\begin{array}{c}\text { Water + } \\
0.1 \mathrm{M} \\
\text { sodium } \\
\text { acetate }\end{array}$ & $\begin{array}{c}\text { Viscometry } \\
\text { (SF) } \\
\text { Sedimentation }\end{array}$ & $1 /$ \\
\hline PHPMA & $\begin{array}{c}1.7 \pm \\
0.1\end{array}$ & $\begin{array}{c}\text { Methanol, } \\
\text { DMF }\end{array}$ & $\begin{array}{l}\text { Viscometry, } \\
\text { Stockmayer- } \\
\text { Fixman (SF) }\end{array}$ & 24 \\
\hline PEtOx & 1.4 & THF & $\begin{array}{l}\text { Viscometry, } \\
\text { Bushin- } \\
\text { Bohdanecky }\end{array}$ & 20 \\
\hline
\end{tabular}

After determination of the chain conformation characteristics of PEtOx in PBS at $37{ }^{\circ} \mathrm{C}$, we focused our attention on the effect of temperature as PEtOx is known to undergo a lower critical solution temperature (LCST) phase transition in aqueous solution (without salt added), at least when having a molar mass above $10 \mathrm{~kg} / \mathrm{mol} .^{25-27}$ All PEtOx samples studied here show thermoresponsivity in PBS solution with a cloud point temperature $\left(62-72{ }^{\circ} \mathrm{C}\right)$ (Figures S5 and S6, Supporting Information). That is in agreement with data reported in literature previously. ${ }^{28}$

Furthermore the viscosity measurements were accomplished in a wide temperature range from $15{ }^{\circ} \mathrm{C}$ to $55{ }^{\circ} \mathrm{C}$ ), which is almost up to the cloud point temperature (Figure $\mathrm{S} 1$, Table S1, Supporting Information). The intrinsic viscosity values decreased upon increasing the temperature indicating that the thermodynamic quality of the solvent was gradually getting worse. Similar trends of the intrinsic viscosity values with increasing temperature were observed for all studied PEtOx macromolecules. Another evidence of the gradual deterioration of thermodynamic quality of solutions is the increase of the Huggins constants, which were determined for all samples and averaged for the studied temperatures: $k^{\prime}: 0.41\left(15^{\circ} \mathrm{C}\right), 0.42$ $\left(25{ }^{\circ} \mathrm{C}\right), 0.48\left(37^{\circ} \mathrm{C}\right), 0.59\left(45^{\circ} \mathrm{C}\right)$ and $0.71\left(55^{\circ} \mathrm{C}\right) .{ }^{29}$ Further analysis of the viscometry measurements was performed based on the determination of the scaling indices $b_{\eta}$ in the KMHS relationships obtained at the studied temperature range (Table $\mathrm{S} 4$ ). Thus, $b_{\eta}$ gradually decreased and passed the transition from swollen polymer coils with the gradual deterioration of the thermodynamical quality of the PBS solution for PEtOx within the temperature range of $15-45^{\circ} \mathrm{C}$ and reaching $\theta$-conditions at $55^{\circ} \mathrm{C}$. Based on the latter, the coefficient $\varepsilon$ that characterizes the thermodynamic quality of the solution was calculated (Figure 2). The obained 
values of $\varepsilon$ allow to estimate the Flory coefficients $\alpha$ of linear coil swelling according to the following equation: ${ }^{30}$

$$
\varepsilon=\frac{\alpha^{2}-1}{5 \alpha^{2}-3}
$$

For the studied PEtOx series in PBS solution the following values of $\alpha$ were found: $1.6\left(15^{\circ} \mathrm{C}\right)$, $1.49\left(25^{\circ} \mathrm{C}\right), 1.27\left(37^{\circ} \mathrm{C}\right), 1.17\left(45^{\circ} \mathrm{C}\right)$ and $1.0\left(55^{\circ} \mathrm{C}\right)$.
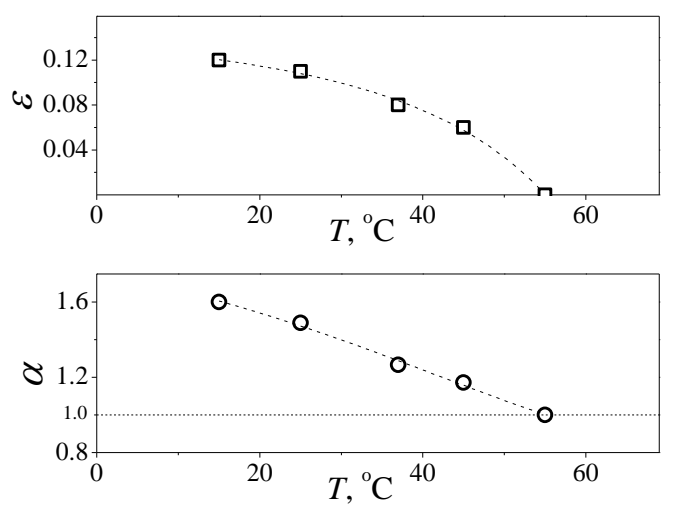

Figure 2. The dependence of parameter $\boldsymbol{\varepsilon}$ and the coefficients of linear coil swelling $\boldsymbol{\alpha}$ obtained for the PEtOx series as function of termperature in PBS solutions.

Our final step was to investigate the equilibrium rigidity dependence as a function of temperature, where the most sensitive hydrodynamic parameter - intrinsic viscosity - was obtained. For that reason Eq.(3) and the Sharp-Bloomfield theory are applied. ${ }^{31}$ The SharpBloomfield theory is written for worm-like necklace and accounts for the excluded volume effects based on the $\varepsilon$ value:

$$
[\eta]=\frac{\Phi(\varepsilon) A^{(3-3 \varepsilon) / 2}}{M_{L}^{\frac{3+3 \varepsilon}{2}}\left(1+5 \varepsilon / 6+\varepsilon^{2} / 6\right)^{3 / 2}} M^{(1+3 \varepsilon) / 2},(9)
$$

where $\Phi(\varepsilon)=2.86 \times 10^{23}\left(1-2.63 \varepsilon+2.86 \varepsilon^{2}\right){ }^{32}$

The resultant graphs are shown in Figure 3 from which the values of equilibrium rigidity were estimated. The found values of equilibrium rigidity at $37^{\circ} \mathrm{C}$ correspond well to the values obtained from the rotational friction experiments. At the same time, both of the used theories predict the similar trend of a slow decrease of equilibrium rigidity value with increasing temperature. This result seems reasonable and it is determined by the fact that the value of rotational hindrance of neighbored chemical bonds in a polymer chain is decreasing with the raise of the temperature. 
(a)

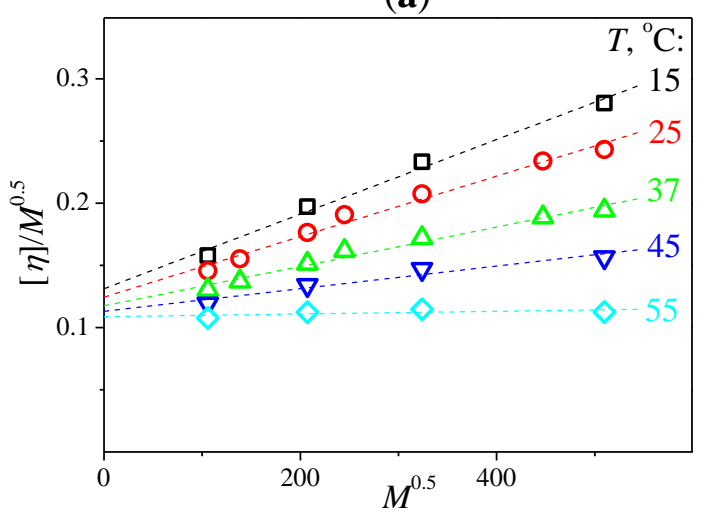

(b)

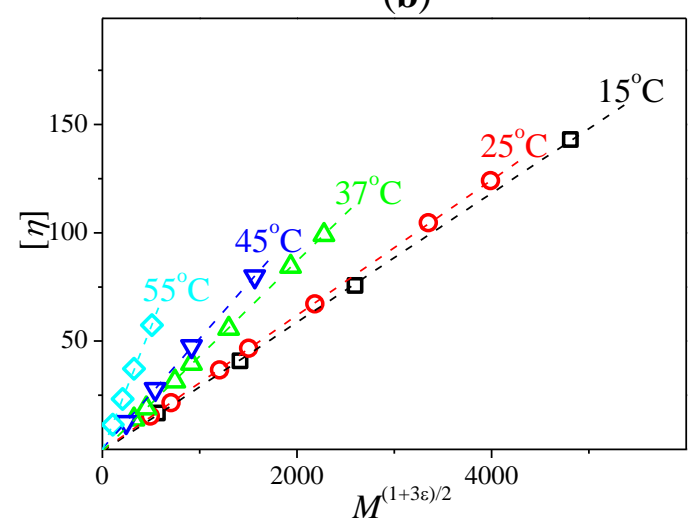

(c)

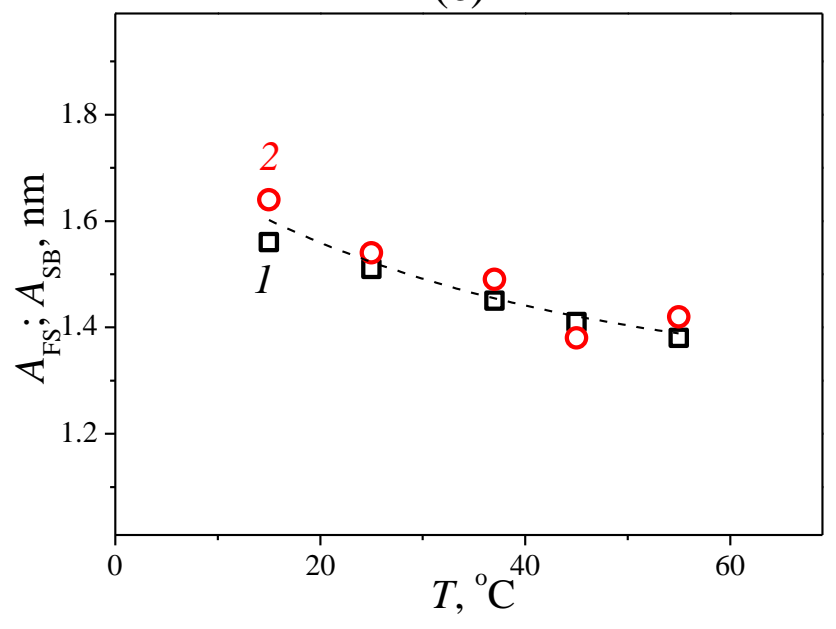

Figure 3. The Fixman-Stockmayer (a), Sharp-Bloomfield (b) extrapolations and the resultant values of equilibrium rigidity (c), where the set of data points (1) is based on (a) and (2) - (b) subplot. At the (a) and (b) plots the numbers correspond to the temperatures, where the current set of intrinsic viscosity values were determined.

To conclude, the complete and thorough analysis gives a direct prove of conformational similarity of biocompatible PEtOx to already known biocompatible polymers such as PEG, PHPMA, and PVP. To our best knowledge, the conformational parameters (equilibrium rigidity/the Kuhn segment length and the diameter of polymer chain) of PEtOx macromolecules were evaluated in physiological conditions for the first time and constitute $A=1.8 \pm 0.3 \mathrm{~nm}$ and $d=0.70 \pm 0.4 \mathrm{~nm}$. Such value of equilibrium rigidity classifies PEtOx as a flexible macromolecule with similar rigidity to poly(ethylene glycol). Such findings justify the choice of PEtOx as prospective analogue of PEG in future. For the first time we were able to prove a direct influence of thermosensitivity on the rigidity of biocompatible polymer: PEtOx. The Kuhn segment length is undoubtedly decreasing with approaching to LCST.

\section{Conflicts of interest}


$\mathrm{RH}$ and BDM are listed as inventors on a patent application that covers the synthesis of high molar mass PEtOx. (WO2016008817A1; Ghent University). The remaining authors declare no competing interests.

\section{Acknowledgments}

This work was supported by Czech Science Foundation GA CR (grant 17-00973S). S. Filippov and R. Hoogenboom acknowledge the support of the mobility project AV ČR - FWO (FWO17-05). R. Hoogenboom further acknowledges funding from FWO and Ghent University for funding of this work. A.A. Lezov gratefully acknowledges the financial support of the RFBR research project (No. 16-33- 60104 mol_a_dk). Some of the experiments were performed at the 'Center for Diagnostics of Functional Materials for Medicine, Pharmacology and Nanoelectronics', Research park of St. Petersburg State University.

\section{Notes and references}

1. O. Sedlacek, B. D. Monnery, S. K. Filippov, R. Hoogenboom and M. Hruby, Macromol. Rapid Commun., 2012, 33, 1648-1662.

2. O. Sedlacek, B. D. Monnery, J. Mattova, J. Kucka, J. Panek, O. Janouskova, A. Hocherl, B. Verbraeken, M. Vergaelen, M. Zadinova, R. Hoogenboom and M. Hruby, Biomaterials, 2017, 146, $1-12$.

3. M. E. Fox, F. C. Szoka and J. M. J. Fréchet, Acc. Chem. Res., 2009, 42, 1141-1151.

4. S. Rakesh, C. P. Sakthidharan, M. Satojadevi and P. R. Sundararajan, Eur. Polym. J., 2015, 68, 161-174.

5. H. Takatsuki, E. Bengtsson and A. Månsson, Biochimica et Biophysica Acta - General Subjects, 2014, 1840, 1933-1942.

6. A. A. Zinchenko, D. Baigl, N. Chen, O. Pyshkina, K. Endo, V. G. Sergeyev and K. Yoshikawa, Biomacromolecules, 2008, 9, 1981-1987.

7. X. Ye, J. Yang and J. Ambreen, RSC Advances, 2013, 3, 15108-15113.

8. G. M. Pavlov, K. Knop, O. V. Okatova and U. S. Schubert, Macromolecules, 2013, 46, 86718679.

9. I. Perevyazko, A. S. Gubarev, L. Tauhardt, A. Dobrodumov, G. M. Pavlov and U. S. Schubert, Polymer Chemistry, 2017, 8, 7169-7179.

10. I. Perevyazko, A.--K. Trützschler, A. Gubarev, E. Lebedeva, A. Traeger, U. S. Schubert and N. Tsvetkov, Polymer, 2017, 131, 252-262.

11. B. Verbraeken, B. D. Monnery, K. Lava and R. Hoogenboom, Eur. Polym. J., 2017, 88, 451-469.

12. R. Hoogenboom and B. Monnery, Journal, 2016.

13. M. Grube, M. N. Leiske, U. S. Schubert and I. Nischang, Macromolecules, 2018, 51, 19051916.

14. W. H. Stockmayer and M. Fixman, Journal of Polymer Science Part C: Polymer Symposia, $1963,1,137-141$.

15. J. M. G. Cowie and S. Bywater, Polymer, 1965, 6, 197-204.

16. H. B. Gray, V. A. Bloomfield and J. E. Hearst, J. Chem. Phys., 1967, 46, 1493-1498.

17. G. M. Pavlov, E. F. Panarin, E. V. Korneeva, C. V. Kurochkin, V. E. Baikov and V. N. Ushakova, Makromolek. Chemie, 1990, 191, 2889-2899.

18. G. M. Pavlov, E. V. Korneeva and N. P. Yevlampieva, Int. J. Biol. Macromol., 1994, 16, 318-323.

19. G. M. Pavlov, in Analytical Ultracentrifugation: Instrumentation, Software, and Applications, eds. S. Uchiyama, F. Arisaka, F. W. Stafford and T. Laue, Springer Japan, Tokyo, 2016, pp. 269-307.

20. J. H. Sung and D. C. Lee, Polymer, 2001, 42, 5771-5779.

21. T. Tsuji, T. Norisuye and H. Fujita, Polym. J., 1975, 7, 558.

22. S. Kawaguchi, G. Imai, J. Suzuki, A. Miyahara, T. Kitano and K. Ito, Polymer, 1997, 38, 2885-2891.

23. K. Kubota, F. Shouei and I. Ando, Polym. J., 1990, 22, 15-20.

24. R. Mendichi, V. Rizzo, M. Gigli and A. Giacometti Schieroni, J. Appl. Polym. Sci., 1998, 70, 329-338

25. P. Lin, C. Clash, E. M. Pearce, T. K. Kwei and M. A. Aponte, J. Polym. Sci., Part B: Polym. Phys., 1988, 26, 603-619.

26. R. Hoogenboom, H. M. L. Thijs, M. J. H. C. Jochems, B. M. Van Lankvelt, M. W. M. Fijten and U. S. Schubert, Chem. Commun., 2008, 5758-5760. 
27. R. Yañez-Macias, I. Alvarez-Moises, I. Perevyazko, A. Lezov, R. Guerrero-Santos, U. S. Schubert and C. Guerrero-Sanchez, Macromol. Chem. Phys., 2017, 218.

28. M. M. Bloksma, D. J. Bakker, C. Weber, R. Hoogenboom and U. S. Schubert, Macromol. Rapid Commun., 2010, 31, 724-728.

29. V. N. Tsvetkov, Rigid-chain polymers, Consult. Bureau. Plenum., London, 1989.

30. O. B. Ptitsyn, Polym. Sci. USSR, 1960, 1, 259-275.

31. P. Sharp and V. A. Bloomfield, The Journal of Chemical Physics, 1968, 48, 2149-2155.

32. P. J. Flory, Principles of Polymer Chemistry, Cornell University Press, 1953. 